\title{
Micropropagation of Cyclopia genistoides, an Endemic South African Plant of Economic Importance
}

\author{
Adam Kokotkiewicz ${ }^{\mathrm{a}}$, Maria Luczkiewicz ${ }^{\mathrm{a}, *}$, Anna Hering ${ }^{\mathrm{b}}$, Renata Ochocka ${ }^{\mathrm{b}}$, \\ Krzysztof Gorynskic, Adam Bucinski ${ }^{\mathrm{c}}$, and Pawel Sowinski ${ }^{\mathrm{d}}$ \\ a The Chair and Department of Pharmacognosy, Faculty of Pharmacy, Medical University \\ of Gdansk, al. gen. J. Hallera 107, 80-416 Gdansk, Poland. Fax: (+48) 583493160. \\ E-mail: mlucz@gumed.edu.pl \\ b The Chair and Department of Biology and Pharmaceutical Botany, Faculty of Pharmacy, \\ Medical University of Gdansk, al. gen. J. Hallera 107, 80-416 Gdansk, Poland \\ c Department of Biopharmacy, Faculty of Pharmacy, Ludwik Rydygier Collegium \\ Medicum in Bydgoszcz, Nicolaus Copernicus University in Torun, \\ Curie-Sklodowskiej st. 9, 85-094 Bydgoszcz, Poland \\ d Nuclear Magnetic Resonance Laboratory, Chemical Faculty, Gdansk University of \\ Technology, Narutowicza st. 11/12, 80-233 Gdansk, Poland \\ * Author for correspondence and reprint requests \\ Z. Naturforsch. 67 c, 65-76 (2012); received June 9/November 3, 2011
}

An efficient micropropagation protocol of Cyclopia genistoides (L.) Vent., an indigenous South African shrub of economic importance, was established. In vitro shoot cultures were obtained from shoot tip fragments of sterile seedlings cultured on solid Schenk and Hildebrandt ( $\mathrm{SH})$ medium supplemented with $9.84 \mu \mathrm{M}$ 6- $(\gamma, \gamma$-dimethylallylamino)purine (2iP) and $1.0 \mu \mathrm{M}$ thidiazuron (TDZ). Maximum shoot multiplication rate $[(8.2 \pm 1.3)$ microshoots/explant)] was observed on this medium composition. Prior to rooting, the multiplied shoots were elongated for 60 days (two 30-days passages) on SH medium with one-half sucrose concentration, supplemented with $4.92 \mu \mathrm{M}$ indole-3-butyric acid (IBA). The rooting of explants was only possible in the case of the elongated shoots. The highest root induction rate $(54.8 \%)$ was achieved on solid SH medium with one-half sucrose and one-half potassium nitrate and ammonium nitrate concentration, respectively, supplemented with $28.54 \mu \mathrm{M}$ indole-3-acetic acid (IAA) and $260.25 \mu \mathrm{M}$ citric acid. The plantlets were acclimatized for 30 days in the glasshouse, with the use of peat/gravel/perlite substrate (1:1:1). The highest acclimatization rate $(80 \%)$ was obtained for explants rooted with the use of IAA-supplemented medium. The phytochemical profile of the regenerated plants was similar to that of the reference intact plant material. HPLC analyses showed that $C$. genistoides plantlets obtained by the micropropagation procedure kept the ability to produce xanthones (mangiferin and isomangiferin) and the flavanone hesperidin, characteristic of wild-growing shrubs.

Key words: Cytokinins, Auxins, Polyphenols

\section{Introduction}

Cyclopia genistoides (L.) Vent. (Fabaceae) is one of over 20 species of indigenous shrubs from the Cyclopia genus, which are characteristic for the fynbos plant formation of the Cape Floristic Region of South Africa. The leaves and stems of several Cyclopia species, including C. genistoides, are used to prepare the honeybush herbal tea,

Abbreviations: BA, 6-benzylaminopurine; 2iP, 6- $(\gamma, \gamma-$ dimethylallylamino)purine; IAA, indole-3-acetic acid; IBA, indole-3-butyric acid; IPA, indole-3-propionic acid; LC-DAD, liquid chromatography-diode array detection; LC-ESI-MS, liquid chromatography-electrospray ionization-mass spectrometry; NAA, $\alpha$-naphthaleneacetic acid; SH, Schenk and Hildebrandt; TDZ, thidiazuron. characterized by sweet, honey-like aroma, low tannin content, and the absence of caffeine (Joubert et al., 2008a; Kokotkiewicz and Luczkiewicz, 2009). The obtained infusions are rich in polyphenols, represented mainly by xanthones (mangiferin and isomangiferin) and a flavanone, hesperidin (Joubert et al., 2008a). The chemical composition of Cyclopia is unique due to the presence of xanthones, which are rarely recorded in legume plants (De Nysschen et al., 1996). Numerous research showed that Cyclopia extracts exhibit significant antioxidative and antimutagenic properties, which were demonstrated with the use of various in vitro, ex vivo, and in vivo models (Joubert et al., 2008a, b; Marnewick et al., 2009). Apart 
from this, some of the honeybush extracts, including those obtained from C. genistoides, show substantial phytoestrogenic activity (Verhoog et al., 2007; Mfenyana et al., 2008). Potential healthpromoting properties of honeybush tea, together with its distinctive flavour, clearly contribute to its popularity as a beverage for everyday use.

The increasing demand for Cyclopia plant material, harvested mainly from wild-growing plants, created the need to establish commercial cultivation in order to avoid the overexploitation of wild populations (Joubert et al., 2008a; Mbangcolo, 2008). One of the species selected for mass production, which could provide sufficient amounts of material for the honeybush tea industry, due to the relatively fast growth, is C. genistoides (Joubert et al., 2008a, b). Although Cyclopia plantations have been established, limited success was achieved with regard to effective $C$. genistoides propagation through cuttings, as this method can provide sufficient amount of plants only during the summer season, when rooting of the cuttings reached $86 \%$, compared to $4 \%$ in winter and spring (Mbangcolo, 2008). Similar difficulties were encountered during the propagation procedures of another commercially important honeybush species, $C$. intermedia. Apart from the fact that the period suitable for Cyclopia propagation is practically restricted to the summer months, $C$. intermedia cuttings also showed significantly lower rooting rates $(46 \%)$, which makes an effective multiplication of this plant even more difficult (Mbangcolo, 2008).

The aim of the present research was to develop an effective micropropagation protocol for commercially important $C$. genistoides. It was also decided to compare the obtained ex vitro plants with the reference intact plant material in terms of the polyphenol content. As far as we know, this is the first report on in vitro propagation of endemic Cyclopia plants.

\section{Material and Methods}

\section{Plant materials}

Seeds of C. genistoides were obtained from Silverhill Seeds (Kenilworth, Cape Town, South Africa). Samples of these seeds are deposited at the herbarium of the Medicinal Plant Garden of the Medical University of Gdańsk, Poland. In order to confirm the identity of the plant material, the obtained $C$. genistoides seedlings were sub- jected to DNA isolation according to the manufacturer's instruction (Genomic Mini AX Plant, cat. no. 050-60; A \& A Biotechnology, Gdynia, Poland). Nuclear rDNA ITS1 and ITS 2 regions were amplified using the primers ITS4 and ITS5 as previously described by White et al. (1990). The PCR product was purified (Clean Up kit, cat. no. 021-250; A \& A Biotechnology), and forward and reverse strands were sequenced on an ABI PRISM 3130 Genetic Analyser (Life Technologies, Carlsbad, CA, USA). Resulting sequences were aligned together with GenBank sequences (GenBank: AJ409895.1) from corresponding species. Next ITS1 and ITS2 sequences were searched against the nt database using standard nucleotide BLAST.

The reference $C$. genistoides intact plant material used in phytochemical analyses was obtained from Cape Honeybush Tea (Mossel Bay, South Africa).

\section{Chemicals}

All chemicals used for media preparation were from Sigma-Aldrich (St. Louis, MO, USA). Solvents used for extract preparation were from POCH (Gliwice, Poland). Acetonitrile and formic acid used for HPLC analyses were from Baker (Phillipsburg, NJ, USA), whereas water was obtained from a Direct-Q 3 water purification system (Millipore, Billerica, MA, USA). Mangiferin and hesperidin were obtained from Sigma-Aldrich. Isomangiferin was isolated from C. subternata intact plant material, whereas the 7-O-glucosides of calycosin, pseudobaptigenin, and formononetin were obtained from C. subternata callus. The identity of the isolated compounds was determined by spectroscopic methods $\left({ }^{1} \mathrm{H},{ }^{13} \mathrm{C}\right.$, and two-dimensional NMR techniques, LC-ESI-MS) (Kokotkiewicz et al., 2009).

\section{Culture media preparation and culture conditions}

C. genistoides in vitro shoot cultures were grown on modified, solid ( $0.6 \% \mathrm{w} / \mathrm{v}$ of agar) Schenk and Hildebrandt (SH) media (Schenk and Hildebrandt, 1972) (Tables I-III). The sucrose content was $3.0 \%(\mathrm{w} / \mathrm{v})$ unless otherwise stated. The $\mathrm{pH}$ value of all media was adjusted to 5.60 prior to autoclaving (0.1 MPa, $\left.121^{\circ} \mathrm{C}, 20 \mathrm{~min}\right)$. The cultures were maintained in baby food jars (culture initiation and microshoot induction stages) or Magenta $^{\circledR}$ vessels (shoot elongation and rooting). 
The experiments were carried out in a growth chamber, at $(24 \pm 1){ }^{\circ} \mathrm{C}$ under continuous light [Phillips white fluorescent lamps, $36 \mathrm{~W},(88 \pm 8)$ $\mu \mathrm{mol} \mathrm{m} \mathrm{m}^{-2}$ light intensity].

The peat/gravel/perlite $(1: 1: 1, \mathrm{w} / \mathrm{w} / \mathrm{w})$ substrate used in acclimatization procedures was prepared by mixing equal amounts of peat, gravel $(1-3 \mathrm{~mm})$, and perlite $(2-6 \mathrm{~mm})$. The explants were placed in pots (50 $\mathrm{mm}$ in diameter), covered by polyethylene bags to prevent moisture loss, and acclimatized in the glasshouse $\left[(24 \pm 1){ }^{\circ} \mathrm{C}\right.$, continuous light].

\section{Germination and in vitro shoot culture initiation}

Before germination, the seeds were scarified with fine (P120) sand paper. Next, they were surface-sterilized in $70 \%(\mathrm{v} / \mathrm{v})$ ethanol for $1 \mathrm{~min}$, followed by a 30 -min treatment with $0.5 \%(\mathrm{w} / \mathrm{v})$ sodium hypochlorite. After sterilization, the seeds were washed three times with sterile, double distilled water, and placed in Petri dishes lined with wet filter paper. The seeds were germinated in the dark, at $(24 \pm 1){ }^{\circ} \mathrm{C}$. After germination, the seeds were moved to a growth chamber for $10 \mathrm{~d}$. One part of the obtained seedlings was subjected to DNA isolation in order to confirm the identity of the examined species, whereas the remaining shoot tip fragments were used for culture initiation.

For shoot culture induction, apical shoot segments $(0.5-1.0 \mathrm{~cm}, 1-2$ nodes) of Cyclopia seedlings were placed on $\mathrm{SH}$ medium supplemented with $\quad 9.84 \mu \mathrm{M} \quad 6$ - $(\gamma, \gamma$-dimethylallylamino)purine (2iP) and $1.0 \mu \mathrm{M}$ thidiazuron (TDZ) (Fig. 1a). The explants were subcultured onto fresh media at 4-weeks intervals. After 6 subsequent passages, the microshoot culture (referred to as the "basic culture") was obtained (Fig. 1c).

\section{Microshoot induction}

In order to determine the influence of growth regulators on the induction of microshoots, 30-day-old explants consisting of 3 microshoots $(5-10 \mathrm{~mm})$ were taken from the basic culture and placed on media supplemented with various growth regulators (M0-M15 media, Table I) - 6 explants per container, 3 containers per modification. After $30 \mathrm{~d}$, the shoots were harvested and evaluated for number and length of the microshoots formed (Table I).

\section{Shoot elongation}

For shoot elongation, 30-day-old explants consisting of 3 microshoots $(5-10 \mathrm{~mm})$ were taken from the medium supplemented with $9.84 \mu \mathrm{M}$ 2iP and $1.0 \mu \mathrm{M}$ TDZ (M1 medium, Table I) and placed onto media of different sucrose and salts concentrations (M10, E1, and E2 media, Table II) - 6 explants per container, 3 containers per modification. After $30 \mathrm{~d}$, the explants were evaluated for length (Table II) and subjected to further elongation or rooting experiments.

In a two-stage elongation system, the shoots elongated for $30 \mathrm{~d}$ were subsequently transferred onto fresh medium of the same composition and cultivated for further $30 \mathrm{~d}$ (Table II). After that time, the explants were measured (Table II) and allowed to root.

\section{Root induction and acclimatization}

In order to determine the conditions necessary for root formation, shoot tip fragments $(15-20 \mathrm{~mm}$ or $40-50 \mathrm{~mm}$ long for shoots elongated for 30 and $60 \mathrm{~d}$, respectively) of C. genistoides explants were placed on solid $\mathrm{SH}$ media which differed in their sucrose, salt, and growth regulator concentrations, respectively (R1-R5 media, Table III), -6 explants per container, 3 containers per modification - and cultivated for $30 \mathrm{~d}$. After that time, they were evaluated for root formation (percent of rooted explants, Table III).

For acclimatization, the plantlets were transferred to pots filled with non-sterile peat/gravel/ perlite substrate -1 explant per pot, 18 pots per modification - and cultured for $30 \mathrm{~d}$. After that time, acclimatization rates were evaluated (percent of surviving plants, Table III).

\section{Extract preparation and estimation of polyphenolic compounds content}

Portions of $500 \mathrm{mg}$ of pulverized, dried (in case of reference intact plant material) or freezedried (in case of in vitro biomasses and regenerated plants) materials were extracted with methanol with the use of a hotplate magnetic stirrer $\left(3 \times 100 \mathrm{ml}, 3 \times 3.0 \mathrm{~h}, 40{ }^{\circ} \mathrm{C}, 200 \mathrm{rpm}\right)$. The extracts were concentrated under reduced pressure $\left(40{ }^{\circ} \mathrm{C}\right)$. The obtained dry residues were dissolved in water and partitioned into chloroform and aqueous fractions. The aqueous fractions were then vacuum-concentrated $\left(40{ }^{\circ} \mathrm{C}\right)$ and the 
resulting dry residues were dissolved in $25 \mathrm{ml}$ of methanol. Prior to HPLC analysis, the extracts were centrifuged for $15 \mathrm{~min}$ at $7500 \times g$.

The HPLC analyses were performed with the use of LC-ESI-MS and LC-DAD systems (Shimadzu, Kyoto, Japan) consisting of two LC20AD solvent pumps, an SIL-20AC autosampler $\left(15^{\circ} \mathrm{C}\right)$, an SPD-M20A diode array detector, a 2010EV mass spectrometry detector, a CTO20AC column oven $\left(30^{\circ} \mathrm{C}\right)$, and a DGU-20A3 degasser. Chromatography was performed on a Supelcosil LC-18 $(150 \times 4.6 \mathrm{~mm}, 3 \mu \mathrm{m})$ column (Sigma-Aldrich). The mobile phase consisted of (A) water/formic acid (100:0.1 v/v) and (B) water/ acetonitrile/formic acid (50:50:0.1 v/v/v). The gradient elution was as follows: $0-15 \mathrm{~min}, 12-25 \%$ B; $15-75 \mathrm{~min}, 25-100 \% \mathrm{~B}$; $75-77 \mathrm{~min}, 100 \% \mathrm{~B}$; 77-80 min, $100-12 \% \mathrm{~B} ; 82 \mathrm{~min}$, stop. The flow rate was $0.6 \mathrm{ml} / \mathrm{min}$, and the injection volume was $3 \mu \mathrm{l}$.

Peaks in chromatograms were identified with the use of the respective standards, and additionally by LC-DAD and LC-ESI-MS. Mass spectrometric detection was performed in the negative ion mode over the range of $\mathrm{m} / \mathrm{z}, 50-1800$. The parameters of electrospray ionization were as follows: desolvation temperature, $230{ }^{\circ} \mathrm{C}$; nitrogen flow rate, $1.5 \mathrm{l} / \mathrm{min}$; capillary voltage, $2000 \mathrm{~V}$.

Quantification of polyphenolic compounds, performed with the use of external standards, was based on the peak area at $280 \mathrm{~nm}$. Peaks were integrated by LC-MS solution software (ver. 3.40, Shimadzu). Standard calibration curves were plotted using dilution series of mangiferin $(20-350 \mu \mathrm{g} / \mathrm{ml})$, hesperidin $(10-330 \mu \mathrm{g} / \mathrm{ml})$, and calycosin $7-O$-glucoside $(5-213 \mu \mathrm{g} / \mathrm{ml})$. The amounts of isomangiferin and the analysed isoflavones were determined using the mangiferin and calycosin 7-O-glucoside calibration curves, respectively.

\section{Statistical analysis}

The data was analysed statistically using oneway analysis of variance (ANOVA). If the results show that there is at least one group whose mean score is different (and it was in our analysis), a number of post-hoc tests may be performed to determine which one matters. Duncan's multiple range test (DMRT) used in this work is a multiple comparison procedure that compares sets of means (tests each mean to each mean). The re- sult from DMRT allows classification of data into subgroups.

\section{Results and Discussion}

\section{Seed germination and in vitro shoot culture initiation}

In vitro shoot cultures of $C$. genistoides were initiated from sterile seedlings. Cyclopia seeds exhibit seed coat-imposed dormancy and as such are characterized by poor germination rates. This phenomenon was successfully overcome by seed scarification, which was previously reported to increase the number of germinating seeds (Sutcliffe and Whitehead, 1994). The seeds were germinated and the obtained seedlings were subjected to molecular analysis. As ITS1 and ITS2 sequences were available in GenBank for numerous species of the genus Cyclopia, it was decided to use this genomic segment for molecular DNA sequencebased identification of the studied species. NCBI (National Center for Biotechnology Information) BLASTn (nucleotide-nucleotide Basic Local Alignment Search Tool) search resulted in a 596bp alignment with $99 \%$ (505/506 nt) similarity to C. genistoides (GenBank: AM050819.1) ITS1 and ITS2 sequences (blast score, 931; E value, $0.0)$. Further elucidation of taxonomic identity was carried out based on unique morphological features that can be observed in the species in question.

In order to induce microshoot formation, shoot tip fragments of 10-day-old seedlings were placed onto SH medium supplemented with $9.84 \mu \mathrm{M} 2 \mathrm{iP}$ and $1.0 \mu \mathrm{M}$ TDZ (Fig. 1a). The above described medium was chosen because it was previously shown to effectively stimulate shoot growth in the case of related Genista plants (Luczkiewicz and Piotrowski, 2005). Shoot cultures of $C$. genistoides proved to be difficult to initiate. The explants exhibited necrotic tendencies, manifested by strong browning of the tissues and the surrounding medium. Similar necrotic changes have been often described in other woody legumes, which are generally considered hard to cultivate in vitro (Dita et al., 2006; Prakash et al., 2006). Another problem was the formation of abnormal leaves, as well as their extensive vitrification in the first 3 months of culture initiation (Fig. 1b). According to formerly described experiments concerning in vitro cultivation of legumes, the above changes can be attributed to TDZ supplementation (Mundhara 
and Rashid, 2006). The only effective way of decreasing the necrotic changes was to involve subsequent transfers of selected fragments onto fresh media in 4-weeks intervals. At the initial stage of the experiment, several procedures were used (various antioxidants supplementation) to avoid formation of abnormal leaves and tissue browning. All of them failed (results not shown). After 6 months, the obtained microshoot cultures were free from undesired morphological features, such as abnormal, vitrified leaves observed during the first months of the newly obtained culture, and the necrotic tendencies vanished spontaneously. The morphology of the obtained microshoot culture was different from that of the intact plant. It was characterized by the presence of numerous small, vitrified leaves and callus formation at the base of the explants (Fig. 1c).

\section{Shoot multiplication}

In order to determine the influence of growth regulators on microshoot formation and morphology in C. genistoides shoots, it was decided to cultivate the shoots on media supplemented with cytokinins, auxins, or a combination of both. The influence of cytokinins on shoot growth was examined by placing the explants on media enriched with adenine - BA or $2 \mathrm{iP}$ - or phenylurea - TDZ - derivatives (Table I). BA (6-benzylaminopurine) is one of the most commonly applied cytokinins, often used for microshoot induction in legume plants (Barik et al., 2007; Buendia-Gonzales et al., 2007), whereas the less popular $2 \mathrm{iP}$ has been shown to effectively induce morphogenesis in certain species (Luczkiewicz and Piotrowski, 2005; Maity et al., 2005). Of the auxin group, indole-3-butyric acid (IBA) was tested, as it has previously been shown to exhibit positive effects on shoot morphology (reduced vitrification), especially when applied together with cytokinins (Rout et al., 2000). The above mentioned growth regulators were applied in specified concentration ranges, commonly used in micropropagation experiments (M1-M15 media modifications, Table I) (Rout et al., 2000)

It was established that the presence of TDZ in the growth medium is essential for the development of an increased number of microshoots per explant (Table I). Microshoots grown on TDZsupplemented medium were characterized by a large number of vitrified, short shoots, as well as the formation of callus at the base of the explant. These phenomena can be attributed to the presence of TDZ, as they have been previously described as characteristic for explants grown on TDZ-enriched media (Neves et al., 2001; Zhao et al., 2003/4). On the contrary, the number of microshoots formed in the media supplemented with $2 \mathrm{iP}$ or BA only was nearly the same as in the control group (M0 medium, Table I).

In the next part of the experiment it was decided to examine if the simultaneous supplementation of the growth media with cytokinins from both the adenine and phenylurea group could exert beneficial effects in terms of microshoot number and their morphology. In many cases, good micropropagation results have been obtained on media supplemented with two cytokinins, for example TDZ together with BA (Husain et al., 2007), or TDZ with 2iP (Luczkiewicz and Piotrowski, 2005). It was observed that the presence of $2 \mathrm{iP}$ only could not induce microshoot formation, however, its application together with TDZ resulted in a significantly increased number of microshoots per explant (M1 medium, Table I). A similar synergistic effect was also observed when BA and TDZ were used simultaneously (M8 medium, Table I). Unfortunately, shoots grown on the latter medium showed excessive vitrification, and as such were not selected for further experiments.

The experiment concerning the influence of growth regulators on $C$. genistoides shoot morphology involved the use of the auxin IBA (M10-M15 media modifications, Table I), which has previously been reported to exhibit a positive effect on shoot appearance (reduced vitrification, absence of abnormal leaves) when applied together with cytokinins. Considering the above application of auxins gives the possibility of skipping the elongation phase, and thus, developing an effective, one-phase micropropagation protocol (Rout et al., 2000). Unfortunately, the addition of IBA to cytokinin-enriched media did not reduce shoot vitrification but also triggered undesired morphological changes, such as shoot tip drying and increased callus formation.

It can be concluded that the presence of TDZ is crucial for the development of large amounts of microshoots in C. genistoides in vitro cultures. The highest number of microshoots was obtained when two cytokinins, 2iP and TDZ, were used simultaneously. Finally, the M1 medium was se- 

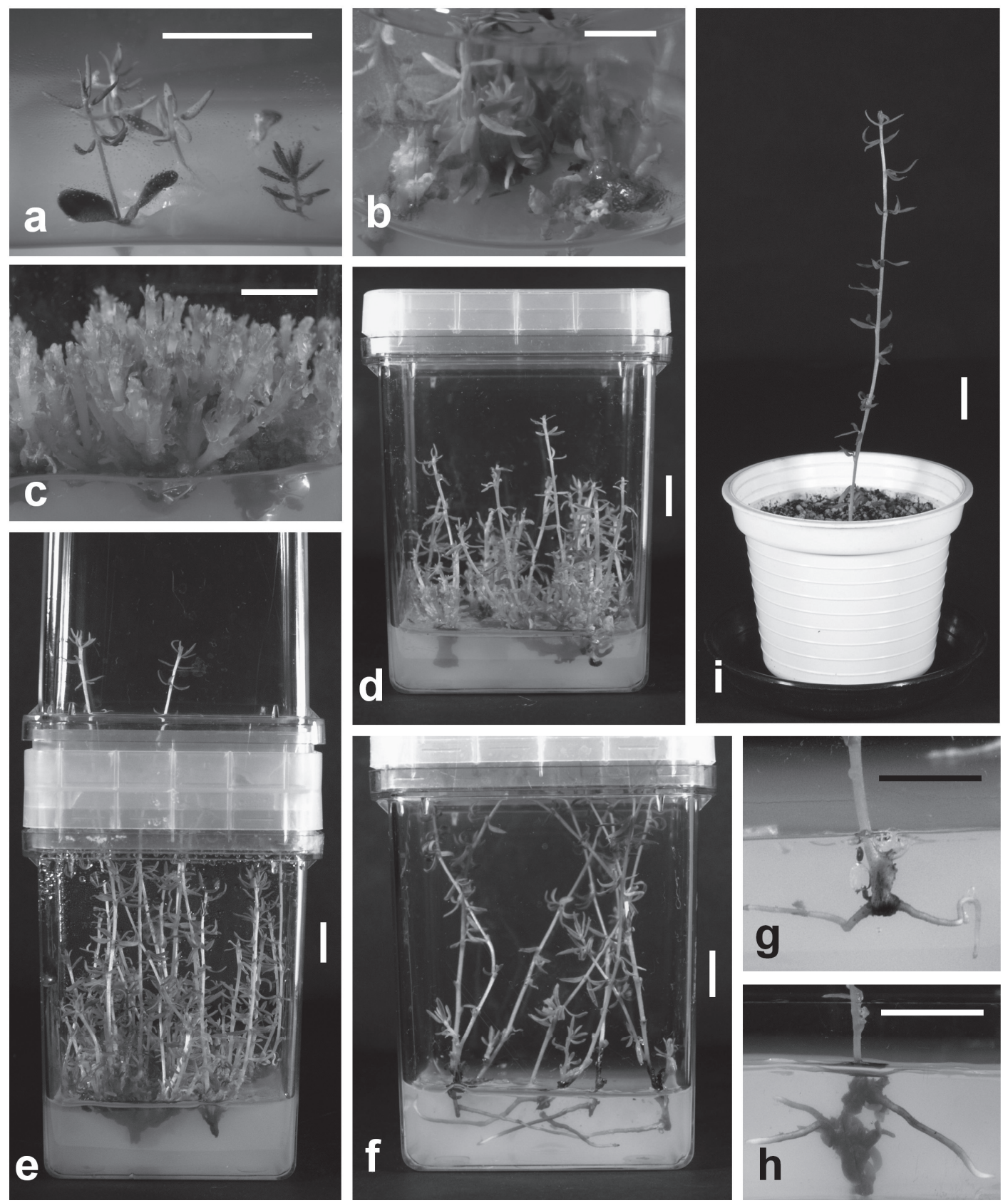

Fig. 1. Stages of $C$. genistoides micropropagation: (a) initial explants (shoot tip fragments) placed on SH medium supplemented with $9.84 \mu \mathrm{M} 2 \mathrm{iP}$ and $1.0 \mu \mathrm{M}$ TDZ; (b) initial microshoots 3 months after culture initiation grown on SH medium supplemented with $9.84 \mu \mathrm{M} 2 \mathrm{iP}$ and $1.0 \mu \mathrm{M}$ TDZ; (c) microshoots ("basic culture") grown on SH medium supplemented with $9.84 \mu \mathrm{M}$ 2iP and $1.0 \mu \mathrm{M}$ TDZ; (d) shoots elongated on SH medium with one-half sucrose concentration, supplemented with $4.92 \mu \mathrm{M}$ IBA (E1) for 30 days; (e) shoots elongated on SH medium with onehalf sucrose concentration, supplemented with $4.92 \mu \mathrm{M} \mathrm{IBA} \mathrm{(E1)} \mathrm{for} 60$ days; (f, g) root induction on SH medium with one-half sucrose and one-half ammonium nitrate and potassium nitrate concentrations, supplemented with $28.54 \mu \mathrm{M}$ IAA and $260.25 \mu \mathrm{M}$ citric acid; (h) root induction on solid SH medium with one-half sucrose and one-half ammonium nitrate and potassium nitrate concentrations, supplemented with $26.85 \mu \mathrm{M}$ NAA and $260.25 \mu \mathrm{M}$ citric acid; (i) regenerated plant during acclimatization in the glasshouse. Bars $=1 \mathrm{~cm}$. 
Table I. The influence of growth regulators on microshoot formation in $C$. genistoides in vitro shoots grown on modified Schenk and Hildebrandt media. The modification applied in the final micropropagation protocol is written in bold.

\begin{tabular}{|c|c|c|c|c|c|c|c|c|c|}
\hline \multirow{2}{*}{$\begin{array}{l}\text { Medium } \\
\text { code }\end{array}$} & \multicolumn{4}{|c|}{ Growth regulators $[\mu \mathrm{M}]$} & \multicolumn{3}{|c|}{ Explant characteristics $^{a}$} & \multirow{2}{*}{$\begin{array}{l}\text { Number of } \\
\text { microshoots } \\
\text { per explant }\end{array}$} & \multirow{2}{*}{$\begin{array}{l}\text { Microshoot } \\
\text { length } \\
{[\mathrm{mm}]^{\mathrm{b}}}\end{array}$} \\
\hline & $2 \mathrm{iP}$ & $\mathrm{BA}$ & TDZ & IBA & $\mathrm{C}$ & $\mathrm{W}$ & $\mathrm{L}$ & & \\
\hline M0 & - & - & - & - & - & + & - & $4.8 \pm 0.8^{\mathrm{a}}$ & $20.6 \pm 6.5^{h}$ \\
\hline M1 & 9.84 & - & 1.0 & - & + & - & - & $8.2 \pm 1.3^{d}$ & $6.9 \pm 0.5^{\mathrm{a}}$ \\
\hline M2 & 9.84 & - & 2.27 & - & + & - & + & $5.7 \pm 1.3^{\mathrm{b}}$ & $10.1 \pm 1.3^{\mathrm{c}}$ \\
\hline M3 & 9.84 & - & 4.54 & - & + & + & + & $5.6 \pm 1.0^{\mathrm{b}}$ & $11.0 \pm 1.7^{\mathrm{cd}}$ \\
\hline M4 & 9.84 & - & - & - & - & - & - & $4.7 \pm 0.9^{\mathrm{a}}$ & $19.0 \pm 4.2^{\mathrm{gh}}$ \\
\hline M5 & 24.6 & - & - & - & - & + & - & $5.6 \pm 0.9^{b}$ & $21.1 \pm 5.2^{\mathrm{h}}$ \\
\hline M6 & - & - & 1.0 & - & + & - & - & $6.7 \pm 1.0^{c}$ & $7.1 \pm 0.7^{\mathrm{a}}$ \\
\hline M7 & - & - & 4.54 & - & + & + & + & $6.1 \pm 1.2^{\mathrm{bc}}$ & $12.4 \pm 3.0^{\mathrm{d}}$ \\
\hline M8 & - & 8.88 & 1.0 & - & + & - & + & $10.8 \pm 2.0^{f}$ & $9.5 \pm 0.8^{b c}$ \\
\hline M9 & - & 8.88 & - & - & - & - & - & $4.5 \pm 0.7^{\mathrm{a}}$ & $18.1 \pm 3.4^{\mathrm{fh}}$ \\
\hline M10 & - & - & - & 4.92 & - & - & - & $4.5 \pm 0.8^{\mathrm{a}}$ & $17.1 \pm 3.0^{\mathrm{efg}}$ \\
\hline M11 & - & - & - & 14.76 & - & + & - & $4.9 \pm 0.7^{\mathrm{a}}$ & $18.6 \pm 4.4^{\mathrm{eh}}$ \\
\hline M12 & - & - & 1.0 & 4.92 & + & + & - & $9.8 \pm 1.8^{\mathrm{ef}}$ & $10.0 \pm 1.0^{c}$ \\
\hline M13 & 9.84 & - & 1.0 & 4.92 & + & - & - & $7.8 \pm 1.6^{\mathrm{d}}$ & $10.2 \pm 1.0^{\mathrm{c}}$ \\
\hline M14 & 9.84 & - & 1.0 & 14.76 & + & + & - & $8.8 \pm 1.8^{\mathrm{de}}$ & $10.0 \pm 1.0^{\mathrm{c}}$ \\
\hline M15 & 9.84 & - & 1.0 & 24.6 & + & + & - & $9.9 \pm 2.5^{\mathrm{ef}}$ & $9.1 \pm 0.6^{\mathrm{b}}$ \\
\hline
\end{tabular}

a C, callus formation; W, shoot tip withering; L, formation of abnormal leaves; feature status: absent (-), present $(+)$.

b The data represent the mean \pm SD of 18 samples. Values followed by different letters indicate significant difference between means $(p<0.05)$, comparison by DMRT.

lected for microshoot induction, as it provided the maximum number of shoots, which represented good vitality (lack of withering) and were free from undesired morphological features (formation of abnormal leaves) (Table I).

\section{Shoot elongation}

In order to obtain explants representing intact plant morphology, which could be used for further rooting and acclimatization experiments, it was decided to cultivate $C$. genistoides shoots on the media supplemented with IBA only (Table II). The morphology of the obtained explants was similar to that of the intact plant, although vitrification was still visible in 30-days elongated shoots, probably due to the presence of TDZ, which was not fully removed from plant tissues (Zhao et al., 2003/4; Mundhara and Rashid, 2006; Husain et al., 2007). Therefore, it was decided to subject the explants to further elongation. Unfortunately, the explants cultivated on the IBA-supplemented M10 medium for $60 \mathrm{~d}$ exhibited several unfavourable features, such as leaf loss, shoot tip withering, and extensive browning
(Table II), probably as a result of the excessive osmotic potential of the growth medium (Rout et al., 2000; Gou et al., 2006; Buendia-Gonzales et al., 2007; Husain et al., 2007). The application of medium with reduced sucrose concentration - E1 - at the $1^{\text {st }}$ elongation stage yielded similar results (in terms of shoot length and morphology) as in the case of M10 medium (Fig. 1d, Table II). However, shoots cultivated on E1 medium for $60 \mathrm{~d}$ were substantially longer and free from necrotic changes, in comparison to shoots cultivated on M10 medium (Fig. 1e, Table II). On the other hand, the medium with reduced sucrose and nitrate concentrations - E2 - proved to be to poor for explant elongation, giving significantly shorter, withering shoots (Table II). As a result, the E1 medium was selected for explant elongation.

\section{Root induction and plant regeneration}

C. genistoides explants elongated for 30 and $60 \mathrm{~d}$ on E1 medium were used in the root induction experiments (Table III). Because no root formation was observed in explants grown on the IBA-supplemented media during shoot multipli- 
Table II. The influence of Schenk and Hildebrandt medium composition and cultivation time on the elongation of C. genistoides shoots. All media were supplemented with $4.92 \mu \mathrm{M}$ IBA. The elongation scheme applied in the final micropropagation protocol is written in bold.

\begin{tabular}{|c|c|c|c|c|c|c|}
\hline \multirow{2}{*}{$\begin{array}{l}\text { Medium } \\
\text { code }\end{array}$} & \multirow{2}{*}{$\begin{array}{l}\text { Elongation } \\
\text { time [d] }\end{array}$} & \multirow{2}{*}{$\begin{array}{l}\text { Medium modifi- } \\
\text { cation applied }^{\mathrm{a}}\end{array}$} & \multicolumn{3}{|c|}{ Explant characteristics ${ }^{\mathrm{b}}$} & \multirow[t]{2}{*}{ Shoot length $[\mathrm{mm}]^{\mathrm{c}}$} \\
\hline & & & $\mathrm{B}$ & W & $\mathrm{L}$ & \\
\hline M10 & 30 & - & - & - & - & $23.9 \pm 6.8^{\mathrm{a}}$ \\
\hline M10 & 60 & - & + & + & + & $41.7 \pm 14.7^{\mathrm{b}}$ \\
\hline E1 & 30 & $1 / 2 \mathrm{~S}$ & - & - & - & $24.1 \pm 5.2^{\mathrm{a}}$ \\
\hline E1 & 60 & $1 / 2 \mathbf{S}$ & - & - & - & $51.7 \pm 10.9^{c}$ \\
\hline $\mathrm{E} 2$ & 30 & $1 / 2 \mathrm{SN}$ & - & + & - & $24.4 \pm 10.1^{\mathrm{a}}$ \\
\hline $\mathrm{E} 2$ & 60 & $1 / 2 \mathrm{SN}$ & - & + & - & $25.3 \pm 8.0^{\mathrm{a}}$ \\
\hline
\end{tabular}

a $1 / 2 \mathrm{~S}$, modified Schenk and Hildebrandt $(\mathrm{SH})$ medium with one-half sucrose concentration; $1 / 2 \mathrm{SN}$, modified $\mathrm{SH}$ medium with one-half sucrose and one-half potassium nitrate and ammonium nitrate concentrations.

b B, explant browning; W, shoot tip withering; L, leaf loss; feature status: absent (-), present (+).

c The data represent the mean \pm SD of 18 samples. Values followed by different letters indicate significant difference between means $(p<0.05)$, comparison by DMRT.

Table III. The influence of applied elongation scheme and medium composition on the rooting of $C$. genistoides in vitro shoots and acclimatization of the regenerated plants. The rooting procedure applied in the final micropropagation protocol is written in bold.

\begin{tabular}{|c|c|c|c|c|c|c|c|c|}
\hline \multirow{2}{*}{$\begin{array}{l}\text { Explant } \\
\text { type }\end{array}$} & \multirow{2}{*}{$\begin{array}{l}\text { Medium } \\
\text { code }\end{array}$} & \multirow{2}{*}{$\begin{array}{l}\text { Growth } \\
\text { regulators } \\
\text { and other } \\
\text { substances }[\mu \mathrm{M}]\end{array}$} & \multirow{2}{*}{$\begin{array}{l}\text { Medium } \\
\text { modification } \\
\text { applied }^{\mathrm{a}}\end{array}$} & \multicolumn{3}{|c|}{ Observed phenomena } & \multirow{2}{*}{$\begin{array}{l}\text { Root } \\
\text { formation } \\
(\%)\end{array}$} & \multirow{2}{*}{$\begin{array}{l}\text { Survival } \\
\text { rate after } 1 \\
\text { month }(\%)\end{array}$} \\
\hline & & & & $\mathrm{B}$ & $\mathrm{C}$ & $\mathrm{L}$ & & \\
\hline \multirow[t]{2}{*}{ Elongated for $30 \mathrm{~d}$} & R1 & NAA (26.85) & $1 / 2 S$ & + & + & - & 0 & - \\
\hline & $\mathrm{R} 2$ & NAA (26.85) & $1 / 2 \mathrm{SN}$ & - & + & - & 0 & - \\
\hline \multirow[t]{5}{*}{ Elongated for $60 \mathrm{~d}$} & R1 & NAA (26.85) & $1 / 2 \mathrm{~S}$ & + & + & + & 1.0 & 0 \\
\hline & $\mathrm{R} 2$ & NAA (26.85) & $1 / 2 \mathrm{SN}$ & - & + & - & 1.0 & 0 \\
\hline & R3 & $\begin{array}{l}\text { NAA }(26.85), \\
\text { citric acid }(260.25)\end{array}$ & $1 / 2 \mathrm{SN}$ & - & + & - & 44.0 & 19 \\
\hline & $\mathbf{R 4}$ & $\begin{array}{l}\text { IAA }(28.54) \text {, } \\
\text { citric acid }(260.25)\end{array}$ & $1 / 2 \mathbf{S N}$ & - & - & - & 54.8 & 80 \\
\hline & R5 & $\begin{array}{l}\text { IPA }(26.43), \\
\text { citric acid }(260.25)\end{array}$ & $1 / 2 \mathrm{SN}$ & - & - & - & 22.0 & 77 \\
\hline
\end{tabular}

a $1 / 2 \mathrm{~S}$, modified Schenk and Hildebrandt $(\mathrm{SH})$ medium with one-half sucrose concentration; $1 / 2 \mathrm{SN}$, modified $\mathrm{SH}$ medium with one-half sucrose and one-half potassium nitrate and ammonium nitrate concentrations.

b B, explant base and medium browning; C, callus formation on roots and/or at explant base; L, leaf loss; feature status: absent (-), present (+).

cation and elongation stages, it was decided to replace it with NAA, which has previously been described as the auxin effectively stimulating root induction in the related Genista plants (Luczkiewicz and Piotrowski, 2005). Due to the fact that low concentrations of carbon sources and mineral constituents in growth media seem to be beneficial for root initiation (Rout et al., 2000), it was decided to use the media with reduced sucrose and salt concentrations (R1-R5 media modifications, Table III). The efficiency of the above described procedure seemed to depend on explant type. Only the shoots elongated for $60 \mathrm{~d}$ formed roots when cultivated on the NAA-enriched media R1 and R2, however, the percentage of explants forming roots was very low $(1.0 \%)$ in both cases (Table III). In the next part of the experiment, it was decided to enrich the NAA-supplemented medium with citric acid (R3 medium modification, Table III), as it has previously been reported that antioxidants can exert positive effects on root induction via their protective effect on auxins (Husain et al., 2007). As a result, rooting percentage was increased from 1.0 to $44.0 \%$ 
(Table III). Unfortunately, the roots formed on NAA-enriched media exhibited a strong tendency to callus formation (Fig. 1h). In order to improve the root morphology, it was decided to replace NAA with equal amounts of different auxins (R4 and R5 media modifications, Table III), suggested as suitable for rooting experiments (Rout et al., 2000). The highest rooting rate was observed in the case of explants grown on IAA-supplemented medium $(54.8 \%)$, followed by $22.0 \%$ recorded for indole-3-propionic acid (IPA) (Table III). Unlike the NAA-induced roots, those obtained on IAAand IPA-enriched media were characterized by the absence of callus and minute necrotic tendencies (Figs. 1f, g).

The relatively low rooting percentage of $C$. genistoides shoots under in vitro conditions can be attributed to the absence of the specific rhizobium strains, the presence of which is often necessary for the proper root development in legume plants (Neves et al., 2001; Spriggs and Dakora, 2007). The fact that root induction was possible only in the case of shoots elongated for $60 \mathrm{~d}$ can be explained by the relatively long period of time necessary for the removal of exogenous cytokinins (in that case, 2iP and TDZ), the presence of which can effectively impair root formation (Zhao et al., 2003/4; Mundhara and Rashid, 2006; Husain et al., 2007).

At the acclimatization stage, the highest survival rates were observed for plantlets rooted with IAA $(80 \%)$ or IPA $(77 \%)$. Explants rooted with the use of NAA showed a substantially lower acclimatization rate, probably as a result of adverse root morphology (callus formation), which made them more susceptible to pathogenic microorganisms.

\section{Estimation of polyphenolic compounds}

C. genistoides explants representing different morphological states, obtained at subsequent micropropagation stages, were subjected to phytochemical analyses in order to evaluate their potential for polyphenol production. The goal was to check if the micropropagation procedures exert any qualitative or quantitative effects on the polyphenol content in the examined biomasses. The obtained results were compared with the reference intact plant material. The extracts were prepared according to the procedure similar to that previously used for the extraction of isoflavones from Genista biomasses (Luczkiewicz and Glod, 2003). Due to the fact that $C y$ clopia polyphenols can be successfully separated on reversed HPLC phases (De Beer and Joubert, 2010), a commonly used RP-18 column and gradient elution were applied. HPLC analyses revealed the presence of xanthones - mangiferin and isomangiferin - and the flavanone hesperidin in all of the examined samples, although significant qualitative and quantitative differences were observed between the biomasses representing different morphological states (Figs. 2a - c, Table IV). The lowest amounts of xanthones were present in microshoots, whereas the regenerated plants were characterized by highest levels of mangiferin and isomangiferin, which significantly exceeded those determined in the intact plant. There were also no significant qualitative differences between regenerated plants and herb of the

Table IV. Quantitative analysis of selected xanthones and flavonoids in C. genistoides biomasses.

\begin{tabular}{|c|c|c|c|c|c|c|}
\hline Material & Mangiferin & Isomangiferin & Hesperidin & $\begin{array}{l}\text { Calycosin } \\
7-O \text {-glucoside }\end{array}$ & $\begin{array}{l}\text { Pseudobapti- } \\
\text { genin } \\
\text { 7-O-glucoside }\end{array}$ & $\begin{array}{l}\text { Formononetin } \\
7 \text { - } O \text {-glucoside }\end{array}$ \\
\hline Microshoots & $0.466 \pm 0.017^{\mathrm{a}}$ & $0.282 \pm 0.009^{\mathrm{a}}$ & $0.083 \pm 0.004^{\mathrm{a}}$ & $0.029 \pm 0.003^{\mathrm{a}}$ & $0.077 \pm 0.004^{\mathrm{a}}$ & $0.099 \pm 0.005^{\mathrm{a}}$ \\
\hline $\begin{array}{l}\text { Shoots elongated } \\
\text { for } 30 \mathrm{~d}\end{array}$ & $0.933 \pm 0.032^{\mathrm{b}}$ & $0.371 \pm 0.011^{\mathrm{b}}$ & $0.084 \pm 0.004^{\mathrm{a}}$ & $0.056 \pm 0.004^{\mathrm{b}}$ & $0.052 \pm 0.004^{\mathrm{b}}$ & $0.090 \pm 0.004^{b}$ \\
\hline $\begin{array}{l}\text { Shoots elongated } \\
\text { for } 60 \mathrm{~d}\end{array}$ & $3.250 \pm 0.096^{\mathrm{c}}$ & $1.062 \pm 0.033^{c}$ & $0.352 \pm 0.010^{\mathrm{b}}$ & nd & nd & nd \\
\hline $\begin{array}{l}\text { Regenerated } \\
\text { plants }\end{array}$ & $8.296 \pm 0.240^{\mathrm{e}}$ & $2.506 \pm 0.076^{\mathrm{e}}$ & $0.432 \pm 0.013^{c}$ & nd & nd & nd \\
\hline $\begin{array}{l}\text { Reference intact } \\
\text { plant material }\end{array}$ & $5.254 \pm 0.014^{\mathrm{d}}$ & $1.922 \pm 0.059^{d}$ & $0.659 \pm 0.022^{\mathrm{d}}$ & nd & nd & nd \\
\hline
\end{tabular}

All values are expressed as percentage of the dry weight. The data represent the mean \pm SD of 5 samples. Values followed by different letters indicate significant difference between means $(p<0.05)$, comparison by DMRT; nd, compound not detected. 

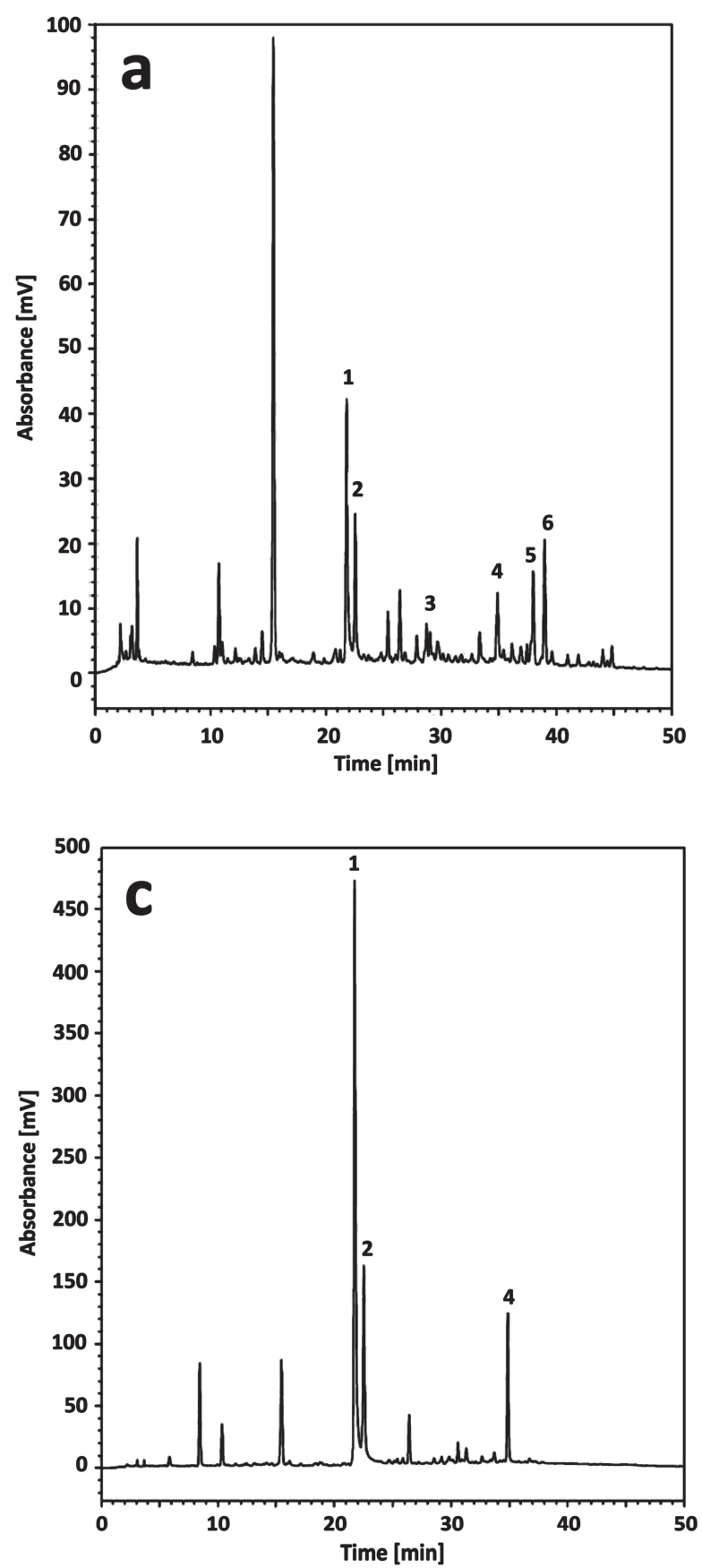

respective species (Figs. 2b, c). The results indicate that only the materials representing intact plant morphology, i.e. shoots elongated for $60 \mathrm{~d}$ and regenerated plants, are capable of producing substantial amounts of polyphenols characteristic for Cyclopia. On the other hand, small amounts

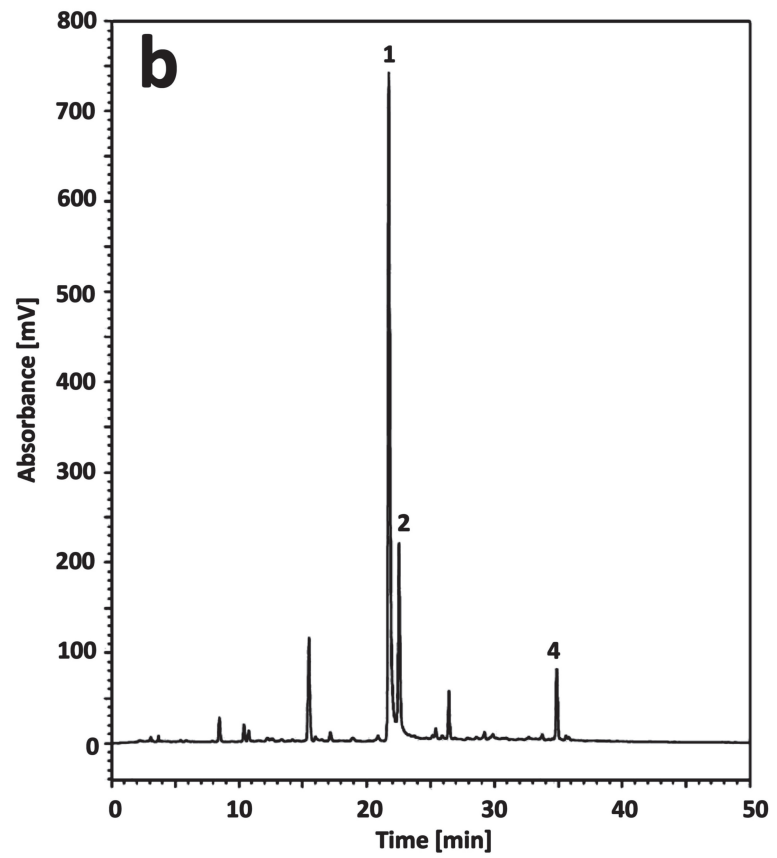

Fig. 2. HPLC chromatograms of polyphenolic fractions from $C$. genistoides biomasses $(\lambda=280 \mathrm{~nm})$ : (a) microshoots grown on solid $\mathrm{SH}$ medium supplemented with $9.84 \mu \mathrm{M} 2 \mathrm{iP}$ and $1.0 \mu \mathrm{M}$ TDZ; (b) regenerated plant grown for 30 days under glasshouse conditions; (c) reference intact plant material. Peaks in chromatograms: 1 , mangiferin; 2 , isomangiferin; 3 , calycosin 7-O-glucoside; 4 , hesperidin; 5 , pseudobaptigenin 7 - $O$-glucoside; 6 , formononetin 7-O-glucoside.

of three isoflavone glucosides absent in the intact plant (7-O-glucosides of calycosin, pseudobaptigenin, and formononetin) were recorded in the microshoots (Fig. 2a, Table IV). The observed differences in the polyphenol composition can be possibly attributed to the presence of exogenous 
cytokinins - 2iP and TDZ - in microshoots and shoots elongated for $30 \mathrm{~d}$.

\section{Conclusion}

Summing up, the research led, for the first time, to the development of an effective procedure for the in vitro propagation of C. genistoides, an endemic South African plant. The positive effect of two correlated cytokinins, $2 \mathrm{iP}(9.84 \mu \mathrm{M})$ and TDZ $(1.0 \mu \mathrm{M})$, on shoot induction was determined. Microshoot formation was followed by the two-phase, 60-d elongation of the explants on IBA-enriched medium with one-half sucrose concentration. The highest rooting rate $(54.8 \%)$ was obtained on solid $\mathrm{SH}$ medium supplemented with $28.54 \mu \mathrm{M}$ IAA, $260.25 \mu \mathrm{M}$ citric acid, onehalf sucrose $(1.5 \% \mathrm{w} / \mathrm{v})$ and one-half potassium nitrate and ammonium nitrate concentrations. Antioxidant supplementation proved to be crucial for root induction. Explants rooted with the use of IAA exhibited the highest acclimatization

Barik D. P., Naik S. K., Mudgal A., and Chand P. K. (2007), Rapid plant regeneration through in vitro axillary shoot proliferation of butterfly pea (Clitoria ternatea L.) - a twinning legume. In Vitro Cell. Dev. Biol. Plant 43, 144-148.

Buendia-Gonzales L., Orozco-Villafuerte J., Cruz-Sosa F., Chavez-Avila V. M., and Vernon-Carter E. J. (2007), Clonal propagation of mesquite tree (Prosopis laevigata Humb. \& Bonpl. ex Willd. M. C. Johnston.) I. Via cotyledonary nodes. In Vitro Cell. Dev. Biol. Plant 43, $260-266$.

De Beer D. and Joubert E. (2010), Development of HPLC method for Cyclopia subternata phenolic compound analysis and application to other Cyclopia sp. J. Food Compos. Anal. 23, 289-297.

De Nysschen A. M., Van Wyk B.-E., Van Heerden F. R., and Schutte A. L. (1996), The major phenolic compounds in the leaves of Cyclopia species (honeybush tea). Biochem. Syst. Ecol. 24, 243-246.

Dita M. A., Rispail N., Prats E., Rubiales D., and Singh K. B. (2006), Biotechnology approaches to overcome biotic and abiotic stress constrains in legumes. Euphytica 147, 1-24.

Gou W., Li Y., Gong L., Li F., Dong Y., and Liu B. (2006), Efficient micropropagation of Robinia ambigua var. idahoensis (Idaho locust) and detection of genomic variation by ISSR markers. Plant Cell. Tiss. Org. Cult. 84, 343-351.

Husain M. K., Anis M., and Shahzad A. (2007), In vitro propagation of Indian kino (Pterocarpus marsu- rate $(80 \%)$, and the obtained plantlets did not differ from original plants in terms of morphology. The ex vitro plants exceeded the reference plant material in terms of mangiferin and isomangiferin content, but there were no significant qualitative differences between the examined biomasses in terms of polyphenol composition. Further research is needed to examine if the developed protocol can be adapted to micropropagate other Cyclopia species. Besides its application in agriculture and nature conservation, in vitro propagation of Cyclopia plants allows mass production of plants in the laboratory, providing material for further studies on the biochemistry, physiology, and secondary metabolism of endemic Cyclopia shrubs, as well as the pharmacological activities of its extracts.

\section{Acknowledgements}

This study was supported by grant no. N N302 041936 from the Polish Ministry of Education and Science.

pium Roxb.) using thidiazuron. In Vitro Cell. Dev. Biol. Plant 43, 59-64.

Joubert E., Gelderblom W. C. A., Louw A., and De Beer D. (2008a), South African herbal teas: Aspalathus linearis, Cyclopia spp. and Athrixia phylicoides - a review. J. Ethnopharmacol. 119, 376-412.

Joubert E., Siân Richards E., Van der Merwe J. D., De Beer D., Manley M., and Gelderblom W. C. A. (2008b), Effect of species variation and processing on phenolic composition and in vitro antioxidant activity of aqueous extracts of Cyclopia spp. (honeybush tea). J. Agric. Food Chem. 56, 954-963.

Kokotkiewicz A. and Luczkiewicz M. (2009), Honeybush (Cyclopia sp.) - a rich source of compounds with high antimutagenic properties. Fitoterapia 80, 3-11.

Kokotkiewicz A., Glod D., Wnuk M., Marszall M., Bucinski A., Sowinski P., and Luczkiewicz M. (2009), Phytochemical analysis of isoflavones from in vitro cultures and intact plants of selected Cyclopia sp. (honeybush). $21^{\text {st }}$ International Symposium on Pharmaceutical and Biomedical Analysis, 11-14 October, 2009, Hilton Walt Disney, Orlando, FL, USA.

Luczkiewicz M. and Glod D. (2003), Callus cultures of Genista plants - in vitro material producing high amounts of isoflavones of phytoestrogenic activity. Plant Sci. 165, 1101-1108.

Luczkiewicz M. and Piotrowski A. (2005), Two-stage system for micropropagation of several Genista 
plants producing large amounts of phytoestrogens. Z. Naturforsch. 60c, 557-566.

Maity S., Ray S., and Banerjee N. (2005), The role of plant growth regulators on direct and indirect plant regeneration from various organs of Laucaena leucocephala. Acta Physiol. Plant. 27, 473-280.

Marnewick J. L., Van der Westhuizen F. H., Joubert E., Swanevelder S., Swart P., and Gelderblom W. C. A. (2009), Chemoprotective properties of rooibos (Aspalathus linearis), honeybush (Cyclopia intermedia) herbal and green and black (Camelia sinensis) teas against cancer promotion induced by fumonisin $\mathrm{B}_{1}$ in rat liver. Food Chem. Toxicol. 47, 220-229.

Mbangcolo M. M. (2008), Aspects of honeybush tea (Cyclopia species) propagation. MSc thesis, Stellenbosch University, South Africa.

Mfenyana C., De Beer D., Joubert E., and Louw A. (2008), Selective extraction of Cyclopia for enhanced in vitro phytoestrogenicity and benchmarking against commercial phytoestrogen extracts. J. Steroid Biochem. Mol. Biol. 112, 74-86.

Mundhara R. and Rashid A. (2006), Recalcitrant grain legume Vigna radiata, mung bean, made to regenerate on change of hormonal and cultural conditions. Plant Cell. Tiss. Org. Cult. 85, 265-270.

Neves L. O., Tomaz L., and Feveriero M. P. S. (2001), Micropropagation of Medicago truncatula Gaertn. cv. Jemalong and Medicago truncatula ssp. narbonensis. Plant Cell. Tiss. Org. Cult. 67, 81-84.

Prakash E., Sreenivasa Rao T. J. V., and Meru E. S. (2006), Micropropagation of red sanders (Pterocar- pus santalinus L.) using mature nodal explants. J. Forest Res. 11, 329-335.

Rout G. R., Samantaray S., and Das P. (2000), In vitro manipulation and propagation of medicinal plants. Biotechnol. Adv. 18, 91-120.

Schenk R. U. and Hildebrandt A. C. (1972), Medium and techniques for induction and growth of monocotyledonous and dicotyledonous plant cell cultures. Can. J. Bot. 50, 199-204.

Spriggs A. C. and Dakora F. D. (2007), Competitive ability of selected Cyclopia Vent. rhizobia under glasshouse and field conditions. Soil Biol. Biochem. 39, 58-67.

Sutcliffe M. A. and Whitehead C. S. (1994), Role of ethylene and short-chain saturated fatty acids in the smoke-stimulated germination of Cyclopia seed. J. Plant Physiol. 145, 271-276.

Verhoog N. J. D., Joubert E., and Louw A. (2007), Evaluation of the phytoestrogenic activity of Cyclopia genistoides (honeybush) methanol extracts and relevant polyphenols. J. Agric. Food Chem. 55, 4371-4381.

White T. J., Bruns T., Lee S., and Taylor J. W. (1990), Amplification and direct sequencing of fungal ribosomal RNA genes for phylogenetics. In: PCR Protocols. A Guide to Methods and Applications (Innis M. A., Gelfand D. H., Sninsky J. J., and White T. J., eds.). Academic Press Inc., San Diego, CA, USA, pp. $315-322$.

Zhao D. L., Gou G. Q., Wang X. Y., and Zheng G. C. (2003/4), In vitro micropropagation of a medicinal plant species Sophora flavescens. Biol. Plant. 47, $117-120$. 